Www.jmscr.igmpublication.org Impact Factor 5.84

Index Copernicus Value: 83.27

ISSN (e)-2347-176x ISSN (p) 2455-0450

crossref DOI: https://dx.doi.org/10.18535/jmscr/v5i4.114

Journal Of Medical Science And Clinical Research

\title{
Correlation of Various Causes of Secondary Infertility in Males
}

\author{
Authors \\ Dr Rakhi M. More ${ }^{1}$, Dr Amol Z. Drugkar ${ }^{2}$, Dr Milind P.More ${ }^{3}$, Dr S.D. Gangane ${ }^{4}$ \\ ${ }^{1}$ Asso. Prof., Dept. of Anatomy, KJSMC, Mumbai, India \\ ${ }^{2}$ Professor, Dept. of Anatomy, CC.M Med. Col. Durg, India \\ ${ }^{3}$ Asso. Prof, Dept of Surgery, Seth G.S. Medical College \& K.E.M.H Parel, Mumbai India \\ ${ }^{4}$ Professor \& Head, Dept. of Anatomy, Terana Med. Col, Mumbai, India
}

Corresponding Author

Dr Rakhi M. More

Associate Professor, Department of Anatomy, K.J.Somaiya Medical College \& Research Centre, Somaiya Ayur Vihar, Everard Nagar, Sion, Mumbai 22, India

Email:dr_rakhimmore@rediffmail.com

\section{ABSTRACT}

Fertility denotes the ability of a man and woman to reproduce. Conversely, infertility denotes lack of fertility, an involuntary reduction in the ability to produce children. The aim of this study was to find out the various causes of secondary infertility in males and correlate them with the studies of previous authors. The study was carried out on 67 males with history of secondary infertility. Detailed history of these patients was taken. Clinical examination and investigations were done. Semen analysis was done. On karyotyping, Chromosomal abnormalities were found in two patients.

Keywords: -Secondary infertility, Chromosomal abnormality, Male infertility, Karyo typing.

\section{Introduction}

'So God created Man in his own image, in the image of God created He Him; male and female created He them And God blessed them, and God said unto them; Be fruitful and multiply and replenish the earth and subdue it [Genesis 1: 2728]

Nothing more vividly demonstrates the importance of fertility to the individual than the reaction by and to those who do not have children [1]. The definition proposed by the American Fertility Society states that "a marriage is to be considered barren or infertile when pregnancy has not occurred after a year of coitus without contraception." Sterility is total inability to reproduce. Infertility may be further classified as Primary infertility, in which no previous pregnancies have occurred, and Secondary infertility, in which a prior pregnancy, although not necessarily a live birth, has occurred ${ }^{[2]}$. It is commonly accepted that infertility affects more than 80 million people worldwide ${ }^{[3]}$. Currently 8 10 million infertile couples are estimated to be in India. It cannot be overemphasized that infertility is a problem of the couple.

Etiologic Factors in Male infertility ${ }^{\text {[2] }}$

(A) Pretesticular

(1) Endocrine -

Hypogonadotrophic hypogonadism 
(2) Coital disorders - Erectile dysfunction Psychosexual

Endocrine, neural or vascular

- Ejaculatory failure

Psychosexual

After genitourinary surgery

Neural

Drug related

(B) Testicular

(1) Genetic

-Klinefelter's syndrome

-Y chromosome deletions

- Immotile cilia syndrome

(2) Congenital - Cryptorchidism

(3) Infective

(4) Anti-spermatogenic agents

- Heat

- Chemotherapy

- Drugs

- Irradiation

(5) Vascular

- Torsion

-Varicocele

(6) Immunologic

(7) Idiopathic

(C) Post-testicular

(1) Obstructive

- Epididymal

- Congenital

- Infective

- Vas Deferens

- Genetic : cystic fibrosis

- Acquired : vasectomy

(2) Epidydmal hostility

- Epididymal asthenozoospermia

(3) Accessory gland infection

(4) Immunologic:

- Idiopathic

- Postvasectomy

- Dietary antioxidant micronutrients e.g. betacarotene, lycopene, retinol and alpha tocopherol may decrease genital tract secretions in men leading to infertility

\section{Material \& Methods}

The study was carried out to evaluate and correlate various causes of secondary infertility in the males. Sixty-seven (67) patients having a history of secondary infertility attending the genetic clinic were initially screened with a detailed history, clinical examination, hormonal tests, sonological investigations. A detail edhistory including past genital surgery, infections (including mumps orchitis), and previous genital trauma, was obtained from the patients. A history of occupational exposures that might affect the reproductive function was also taken. Due consent of these patients was taken and then they were screened for chromosomal abnormalities

\section{Method - Karyotyping}

1-2 $\mathrm{ml}$ of peripheral blood of the patient was collected in sterilized, heparinized $5 \mathrm{ml}$ syringe by venipuncture. Planting of the culture was done on the same day. The contents of each culture vial were mixed gently and incubated for 3 days at $37{ }^{\circ} \mathrm{C}$. For each patient two vials were planted with PHA-M.

The planted cultures were shaked well after every 24 hours. This enhances better growth. Harvesting of the culture was done using colchicines (Gibco BRL). After harvesting, Giemsa banding was done and metaphases were screened. Well spread metaphases were photographed \& arranged as per classification of human chromosomes recommended by International System for Human Cytogenetic Nomenclature (ISCN 1978). 
Observations and Results

Table No 1- Various parameters studied

\begin{tabular}{|l|c|c|c|}
\hline Sr. No & Parameter studied & No of patients & Percentage \\
\hline 1 & Age & $36(26-30)$ & $53.73 \%$ \\
\hline 2 & Consanguinity & 10 & $14.93 \%$ \\
\hline 3 & Hormonal analysis & 0 & 0 \\
\hline 4 & Associate medical conditions & 01 & $1.49 \%$ \\
\hline 5 & Pathology of the Reproductive & 02 & $2.99 \%$ \\
\hline 6 & Tract & O2 (Oligospermia) & $2.99 \%$ \\
\hline 7 & Cemen Analysis & (Azoospermia) & \\
\hline & Chromosomal abnormalities & (Numerical) & $2.99 \%$ \\
\hline
\end{tabular}

Table No 2- Proportion of Chromosomal abnormalities in Males with Secondary Infertility

\begin{tabular}{|l|l|}
\hline Total patients & 67 \\
\hline Chromosomal abnormality & 02 \\
$\bullet \quad$ Structural & 01 \\
$\bullet \quad$ Numerical & 01 \\
\hline
\end{tabular}

\section{Discussion}

Infertility is defined as 1 year of unprotected intercourse without pregnancy. This condition may be further classified as primary infertility, in which no previous pregnancies have occurred, and secondary infertility, in which a prior pregnancy, although not necessarily a live birth, has occurred. A number of demographic variables, including age and socioeconomic status, have been associated with infertility ${ }^{[2]}$ The prevalence varies widely, being less in developed countries and more in developing countries where limited resources for investigation and treatment are available $^{[4]}$. Although patients seeking treatment for infertility are predominantly of high socioeconomic status, infertility is more common among groups of relatively low socioeconomic status ${ }^{[5]}$.

There is little doubt that increasing age is accompanied by reduced female fecundity; however, the age-related decline in fecundity for men is more controversial. Male fertility peaks at about 35 years of age and declines sharply after 45 years of age; however, men have reportedly fathered children into their $80 \mathrm{~s}{ }^{[5]}$. Also, the risk for chromosomal trisomies appears to be related, at least in part, to increased paternal age ${ }^{[6]}$. Recent observations have demonstrated an increase in the rate of autosomal recessive disorders among the progeny of men 35 years of age and older ${ }^{[7],[8]}$. These findings suggest an agerelated decline in gamete quality among men, albeit one that is more subtle than that experienced by women ${ }^{[2]}$.

The male patients referred for secondary infertility were maximum in the age group 26-30, that is 36 $(53.73 \%)$. In India, early marriages may contribute to the shift to the lower age group of infertility.

Among the factors, which are known to increase the risk of chromosomal abnormalities in offspring, consanguinity has a significant role ${ }^{[22]}$. Consanguinity may increase the rate of homozygous genotype expression, making the offspring of consanguineous marriages at increased risk for recessively inherited disorders [9],[10]. Closely biologically related couples may produce offspring with recessive autosomal mutations of nonphenotypic origins, mutations that may lead to a range of specific, rare recessive disorders ${ }^{[11]-[15]}$. Recent studies suggest that consanguinity is highly correlated with rare genetic sperm-defect syndromes, involving the sperm head (e.g., round heads, heads with craters)or sperm tail (e.g., stunted, immotile, or detached tails) ${ }^{[16],[17]}$. These syndromes impact sperm motility, are incurable, willbe present 
throughout a man's lifetime, and may be transmitted over generations to male offspring ${ }^{[16]}$. In the present study out of 67 males, 10 males had a history of consanguinity.

In the males anatomical abnormalities like hypospadias, obstruction or absence of vas deferens are implicated as causes of infertility. Testicular damage or mal development can be found following mumps orchitis, cryptorchidism, or in association with klinefelters syndrome. Males with the latter genetic abnormlity (XXY) usually have small testis and azospermia. Varicocele of the pampiniform plexus has been found in $20 \%$ to $40 \%$ of infertile males (Howard 1992).

Anatomical abnormalities were found in 2 out of $67(2.99 \%)$ men referred for secondary infertility. A varicocele is an abnormal dilatation of the veins within the spermatic cord. Varicoceles nearly always occur on the left side, presumably because of the direct drainage of the spermatic vein into the left renal vein. The pathophysiologic effects of varicocele on testicular function are uncertain but appear to be mediated by an associated rise in testicular temperature or a reflux of toxic metabolites from the left adrenal or renal veins ${ }^{[18]}$. In either event, the effect on sperm production is bilateral. Our understanding of the role of varicoceles in infertility is complicated by two issues: the prevalence of varicoceles in the normal male population and the efficacy of varicocele repair in infertile men. One WHO study found varicocele to be present in $25.4 \%$ of men with abnormal semen analyses, as opposed to $11.7 \%$ of men with normal semen ${ }^{[19]}$. This study failed to demonstrate a difference in the frequency of spontaneous pregnancies among couples in which the men did or did not have varicoceles. The presence of a varicocele was, however, associated with decreased testicular volume, impaired semen quality, and a reduction in serum testosterone levels.

Hormonal studies - In males although endocrine disorders are an uncommon cause for infertility, testing for thyroid, gonadotrophins, prolactin and testosterone may occasionally uncover unsuspected abnormalities. FSH levels are elevated with germ cell aplasia and testosterone levels are decreased in men who are hypogonadotropic. Hyperprolactinemia is commonly associated with impotence ${ }^{[20]}$.

In this study, no hormonal imbalance was observed in males with secondary infertility.

Associated Medical illness -Diabetes mellitus, a state of chronic hyperglycemia, is found to be an effective cause associated with male infertility ${ }^{[21]}$. In 2014, WHO estimated the global prevalence of diabetes to be $9 \%$ among adults aged $18+$ years. According to International Diabetes Federation, India ranks 79th position in the world with the comparative prevalence of $9.09 \%$. It is a wellrecognized cause of male sexual dysfunction at multiple levels including endocrine control of spermatogenesis, penile erection and ejaculation, and spermatogenesis ${ }^{[22]}$.

1 out of $67(1.49 \%)$ referred for secondary infertility had an associated medical illness.

There is a complex correlation between genetics and infertility. Sex chromosome abnormalities are an important cause of male infertility [23],[24]. Intracytoplasmic sperm injection (ICSI) is an effective therapeutic method, especially in couples with male infertility and/or unsuccessful in vitro fertilization (IVF) experiences ${ }^{[23]}$. Cytogenetic evaluation of couples prior to ICSI shows thatboth genders are equally at risk for sex chromosome abnormalities. An increased incidence of the 47, XYY karyotype in infertile males has been reported ${ }^{[24]}$, although the majority of individuals with this karyotype are fertile and show normal spermatogenesis ${ }^{[24],[25]}$. In those males who have spermatogenetic failure, abnormalities of azoospermia factor genes in the euchromatic region on the long arm of the $\mathrm{Y}$ chromosome (Yq) have been reported ${ }^{[24]}$. The Yqmicrodeletions of azoospermia factor (AZF) regions are major causes of infertility associated with severe oligospermia and azoospermia ${ }^{[26]}$ and may also 
be associated with somatic and germinal

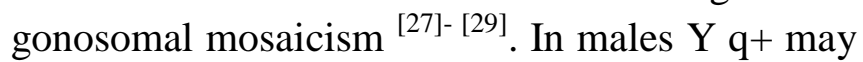
carry the increased risk of abortion as reported by Patil (1977) and Nielson (1978). This report was contradicted by De Brakeleer (1990). In the present study $\mathrm{Yq}+$ was found in only 1 case and hence it is difficult to comment that it increases the risk of abortion. Some chromosomal aberrations are inherited, while others arise de novo ${ }^{[17]}$.

\section{Semen Analysis}

Patients with a spermatozoa count $<5$ million $/ \mathrm{mL}$ already showa 10 -fold higher incidence $(4 \%)$ of mainly autosomal structural abnormalities compared with the general population ${ }^{[30],[31]}$. Men with NOA are at highest risk, especially for sex chromosomal anomalies. Based on the frequencies of chromosomal aberrations in patients with different sperm concentration, karyotype analysis is indicated in men with azoospermia or oligozoospermia (spermatozoa $<10$ million/mL) [31]. Several factors affect game to genesis, from which, factors that lead to chromosomal abnormalities are one of the best known.

In present study two patients showed oligospermia.

\section{Conclusion}

Patients with the history of secondary infertility need to take detailed history, clinical examinations to be done, semen analysis to be done. Chromosomal abnormalities form the important contributors to the causes of infertility. It is therefore important to do thorough cytogenetic investigation of patients with infertility as it forms the basis of genetic evaluation of the patient. Further counselling will depend on the type of abnormality detected.

\section{References}

1. Insler V, Lunenfeld B (1993). Infertility: Male and Female 2nd edition, pg 3-7

2. Novak's Gynecology, 13th edition
3. World Health Organization (WHO). Current practices and controversies in assisted reproduction. Report of a meeting on "Medical, Ethical and Social aspects of assisted reproduction" Geneva, World Health Organization 2002.pg no 13

4. Warburton D, Fraser FC (1964). Spontaneous abortion risks in man: Data from reproductive histories collected in a medical genetic unit. Am J Hum Genet 16.1

5. Dutta S, Guha RA. Clinico- anatomical study on the etiological factors pertaining to primary infertility in females using some common investigative procedures. $\mathbf{J}$ AnatSoc India 2007; 56: 114-147.

6. Griffin DK, Abruzzo MA, Millie EA, et al. Non-disjunction in human sperm: evidence for an effect of increasing paternal age. Hum Mol Genet 1995;4:2227- 232.

7. Stene J, Fischer G, Stene E, et al. Paternal age affect in Down's syndrome. Ann Hum Genet 1977;40:299-306.

8. Bedford JM. Sperm capacitation and fertilization in mammals. Biol Reprod 1970;2[Suppl]:128-158.

9. Bittles AH, Grant JC, Sullivan SG, Hussain R. Does inbreeding lead to decreased human fertility? Ann Hum Biol 2002;29:111-30.

10. Bittles AH, Manson WM, Greene J, Rao NA. Reproductive behavior and health in consanguineous marriages. Science 1991;252:789-94.

11. Gunaid AA, Hummad NA, Tamim KA. Consanguineous marriage in the capital city Sana'a, Yemen. J BiosocSci 2004;36:111-21.

12. El-Hazmi MA, Al-Swailem AR, Warsy AS, Al-Swailem AM, Sulaimani R, AlMeshari A. Consanguinity among the Saudi Arabian population. J Med Genet 1995;32:623-6.

13. Hussain R, Bittles AH. Assessment of association between consanguinity and 
fertility in Asian populations. J Health PopulNutr 2004;22:1-12.

14. Al Abdulkareem AA, Ballal SG. Consanguineous marriage in an urban area of Saudi Arabia: rates and adverse health effects on the offspring. J Community Health 1998;23:75-83.

15. Al-Gazali LI, Bener A, Abdulrazzaq YM, Micallef R, Al-Khayat AI, Gaber T. Consanguineous marriages in the United Arab Emirates. J Biosoc Sci 1997;29:4917.

16. Baccetti B, Capitani S, Collodel G, Cairano G, Gambera L, Moretti E, et al. Genetic sperm defects and consanguinity. Hum Reprod 2001;16:1365-71.

17. Latini M, Gandini L, Lenzi A, Romanelli F. Sperm tail agenesis in a case of consanguinity. FertilSteril 2004;81:1688-9

18. Takihara H, Sakatoku J, Cockett ATK. The pathophysiology of varicocele male infertility. FertilSteril 1991;55:861-868.

19. World Health Organization. The influence of varicocele on parameters of fertility in a large group of men presenting to infertility clinics. Fertil Steri 1992;57:1289-1293.

20. Speroff et al. Clinical Gynaecologic Endocrinolgy and infertility, 6th edition

21. Agbaje IM, Rogers DA, McVicar CM, McClure N, Atkinson AB, et al. (2007) Insulin dependant diabetes mellitus: implications for male reproductive function. Hum Reprod 22: 1871-1877.

22. Sexton WJ,Jarow JP (1997) Effect of diabetes mellitus upon male reproductive function. Urology 49: 508-513.

23. Morel F, Gallon F, Amice V, Le Bris MJ, Le Martelot MT, Roche S, Valéri A, Derrien V, Herry A, Amice J, De Braekeleer M. Sex chromosome mosaicism in couples undergoing intracytoplasmic sperm injection. Hum Reprod 2002; 17(10): 2552-2555.
24. Gekas J, Thepot F, Turleau C, Siffroi JP, Dadoume JP, Wasels R Benzacken B. Association des Cytogeneticiens de Langue Francaise. Chromo-somal factors of infertility in candidate couples for ICSI: an equal risk of constitutional aberrations in women and men. Hum Reprod 2001; 16(1): 82-90.

25. Robinson DO, Jacons PA. The origin of the extra $\mathrm{Y}$ chromosome in males with a 47,XYY kary-otype. Hum Mol Genet 1999; 8(12): 2205-2209.

26. Vogt PH, Chandley AC, Hargreave TB, Keil R, Ma K, Sharkey A. Microdeletions in interval 6 of the $\mathrm{Y}$ chromosome of males with idiopathic sterility point to disruption of AZF, a human spermatogenesis gene. Hum Genet 1992; 89(5): 491496.

27. Siffroi JP, Le Bourhis C, Krausz C, Barbaux S, Quintana-Murci L, Kanafani S Rouba H, Bujan L, Bourrouillou G, Seifer I, Boucher D, Fellous M, McElreavey K, Dadoune JP. Sex chromosome mo-saicism in males carrying $\mathrm{Y}$ chromosome long arm deletions. Hum Reprod 2000; 15(12): 2559-2562.

28. Jaruzelska J, Korcz A, Wojda A, Jedrzejcak P, Bierla J, Surmacz T, Pawelczyk L, Page DC, Ko-tecki M. Mosaicism for 45,X cell line may accen-tuate the severity of spermatogenic defects in men with AZFc deletion. J Med Genet 2001; 38(11): 798-802.

29. Patsalis PC, Skordis N, Sismani C, Kousouli-dou L, Koumbaris G, Eftychi C, Stavrides G, Ioulia-nos A, Kitsiou-Tzeli S, Galla-Voumvouraki A, Ko-smaidou Z, Hadjiathanasiou $\mathrm{CG}$, McElreavey $\mathrm{K}$. Identi $\square$ cation of high frequency of $\mathrm{Y}$ chromosome deletions in patients with sex chromosome mosa-icism and correlation with the clinical phenotype and Y-chromosome instability. Am J Med Genet A 2005; 135(2): 145-149. 
30. Clementini E, et al. Prevalence of chromosomal abnormalities in 2078 infertile couples referred for assisted reproductive techniques. Hum Reprod 2005 20(2): p. 437-42.

31. Vincent MC, et al. Cytogenetic investigations of infertile men with low sperm counts: a 25-year experience. J Androl 2002 23(1): p. 18-22; discussion 44-5. 